\title{
Toxicological Effects of Cd Pollution on Soil Urease Activity
}

\author{
Baoshan Yang ${ }^{1,2}$, Fei $\mathrm{He}^{1,2}$,Qinglin Chen ${ }^{1,2}$, Hui Wang ${ }^{1,2 *}$ \\ ${ }^{1}$ College of Resources and Environment, University of Jinan, Jinan 250022, China \\ ${ }^{2}$ Shandong Provincial Engineering Research Center for Ecological Carbon Sink and Capture Utilization, Jinan 250022, China \\ *Corresponding author:hwang_118@163.com
}

\begin{abstract}
To characterize the effect of heavy metal Cd on soil microbial activity, urease activity was analyzed based on the enzymatic products of ammonia. . The results showed Cd concentrations had little effect on the urease activity and the incubation time had strong effect on the activity of urease activity with the incubation time. Cd had a significant effect on urease activity during the incubation phase. Urease activity was significantly higher than that of without addition of $\mathrm{Cd}$ in soil. When the activation effect of $\mathrm{Cd}$ was studied, there is a threshold of $\mathrm{Cd}$ among the concentrations of $\mathrm{Cd}$. The threshold can promote the urease activity increased and be conducive to microbial decomposition of urea. Once the threshold is exceeded, the decomposition efficiency of urea will reduce the effect, absorption and utilization of microbial.
\end{abstract}

Keywords-soil; cadmium; urease; toxic effect.

\section{INTRODUCTION}

Heavy metal pollutants are a kind of potential harm to human, animals and plants, will pass through the food chain bioaccumulation, amplification ${ }^{[1]}$, Its harm mainly includes: chronic and toxic, carcinogenic, teratogenic, mutagenic effect $^{[2,3]}$, allergy and inflammation, reduced immunity etc.. ,Cd is a kind of serious heavy metal toxicity, USA Management Committee (ATSRD) will be listed as sixth human health hazards of toxic substances, the United Nations Environment Programme (NDEP) and the International Labour Health heavy metals Committee as its focus on environmental pollutants, WHO will food contaminants priority research as the.

In soil ecosystem, soil enzyme catalysts for biochemical reactions involved in the soil organic matter, in the ecological environment, promote the formation of metabolic processes, material cycling in soils. Soil enzyme activity is sensitive to physical, chemical, biological and other soil factors and the changes of the external environment, it is often used to indicate the soil pollution ${ }^{[4]}$, become the soil ecosystem change warning and sensitive index ${ }^{[5,6]}$.Among them, the urease is an important component of soil nitrogen cycle, can promote the formation of $\mathrm{NH}^{4+}$ urea hydrolysis, so as to promote the absorption of nitrogen by plants.Cd will make the soil urease activity decreased, and the higher the concentration, inhibiting effect on urease activity is ${ }^{[7]}$.Study on the determination of the amount of ammonia to urea as matrix of enzymatic reaction, urease activity in the soil to characterize the relationship, to search the soil heavy metal content and microbial activity, the Pollution Characterization of cadmium and cadmium pollution threshold.

\section{MATERIALS AND METHODS}

\section{A. Sample sources and methods}

The sampling point is located in the suburb of Ji'nan Shandong, belongs to the alluvial plain of the Yellow River wheat planting area, is a typical alluvial soil.Using random sampling method with 12 samples of the surface soil, soil 0 $20 \mathrm{~cm}$, mixed $2 \mathrm{~mm}$ screen for training, testing, another part of the basic physical and chemical properties of soil. Research method using urea as the matrix, based on the enzymatic products of ammonia and phenol hypochlorite reaction blue starch, to analyze the urease activity.

\section{B. Apparatus and reagents}

\section{1) Instrument}

PHS-3D pH meter, AIM600 electrothermal digestion instrument, UV752N spectrophotometer, analytical balance.

2) Reagent

Ferrous sulfate, potassium dichromate, phenanthroline, concentrated sulfuric acid, urea, citric acid, potassium hydroxide, sodium phenolate, methanol, ethanol, acetone, sodium hypochlorite, ammonium sulfate, sodium hydroxide, were analytically pure.

\section{RESULTS AND ANALYSIS}

\section{A. Determination of soil properties}

Through measuring the physical and chemical properties of soil bulk density is 1.3867, $\mathrm{pH}$ value 7.47, water content $9.82 \%$, the mass fraction of organic matter was $1.89 \%$.

\section{B. Determination of urease activity in soil samples}

\section{1) Draw standard curve}

Accurately weighting ammonium sulfate $0.4717 \mathrm{~g}$ with analytical balance in the beaker, dissolved in distilled water after the transfer to $1000 \mathrm{~mL}$ volumetric flask, constant volume, nitrogen standard solution prepared with $\mathrm{NH}_{4}{ }^{+} 0.1 \mathrm{mg} / \mathrm{ml}$. For $0,0.5,1,1.5,2,2.5,3,3.5,4 \mathrm{~mL}$ Nitrogen Standard Solution to a $50 \mathrm{~mL}$ volumetric flask, Added to each flask $4 \mathrm{~mL}$ prepared sodium phenolate solution and $3 \mathrm{~mL}$ solution of sodium hypochlorite, while still shake, 20min color, sizing, absorbance at a wavelength 
of 578nm solution was determined by spectrophotometer, Measured values are shown in table 2-3, draw the standard curve as shown in figure 1 :

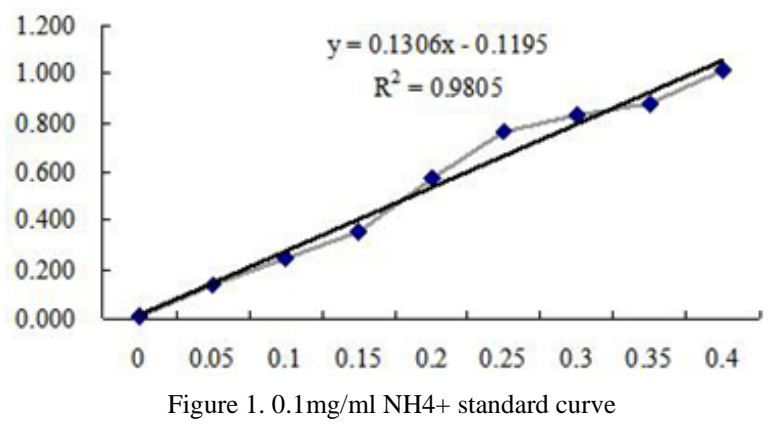

\section{2) Draw standard curve}

Respectively, weigh the soil samples incubated $5 \mathrm{~g}$ in a conical flask, add $1 \mathrm{~mL}$ of formaldehyde, shake after standing for $15 \mathrm{~min}$, to kill most microbes in the soil samples, after joining $10 \mathrm{~mL}$ urea and $20 \mathrm{~mL}$ citric acid buffer solution into the conical flask. The conical flask is placed at $37{ }^{\circ} \mathrm{C}$ culture box after 24 hours, take out, filtering, $1 \mathrm{~mL}$ filtrate to $50 \mathrm{~mL}$ volumetric flask, add $4 \mathrm{~mL}$ of sodium phenolate solution and $3 \mathrm{~mL}$ solution of sodium hypochlorite, while still shake for 20min,the amount of released ammonium was determined by the Bertholet reaction, and measured spectrophotometrically at $578 \mathrm{~nm}$. Another soilless control group and a control group without matrix are also measured with the above method. Each sample is provided with 3 parallel, the measured data and the average value, the data obtained are shown in table 1 :

TABLE I. DifFERENT INCUBATION TIMES ABSORBANCE

\begin{tabular}{|c|c|c|c|c|c|c|c|}
\hline & Culture time (d) & 1 & 3 & 5 & 7 & 14 & 28 \\
\hline \multirow{3}{*}{$\begin{array}{l}\text { Adding a } \\
\text { matrix group }\end{array}$} & Cd（300mg/kg） & 0.350 & 0.285 & 0.640 & 0.720 & 0.863 & 0.858 \\
\hline & Cd（600mg/kg） & 0.364 & 0.284 & 0.659 & 0.727 & 0.774 & 0.756 \\
\hline & Contrast & 0.315 & 0.736 & 0.668 & 0.670 & 0.744 & 0.680 \\
\hline \multirow{3}{*}{$\begin{array}{l}\text { No matrix } \\
\text { group }\end{array}$} & Cd（300mg/kg） & 0.073 & 0.089 & 0.091 & 0.088 & 0.089 & 0.066 \\
\hline & Cd（600mg/kg） & 0.084 & 0.088 & 0.077 & 0.092 & 0.084 & 0.080 \\
\hline & Contrast & 0.085 & 0.079 & 0.085 & 0.065 & 0.082 & 0.086 \\
\hline contrast & & 0.237 & 0.238 & 0.286 & 0.290 & 0.296 & 0.268 \\
\hline
\end{tabular}

According to the standard curve, the content of NH3-N calculation of soil samples as shown in table 2:

TABLE II. DifFerent CUlture PERIOD THE NH3-N CONTENT OF THE SAMPLE

\begin{tabular}{|c|c|c|c|c|c|c|c|}
\hline & Culture time (d) & 1 & 3 & 5 & 7 & 14 & 28 \\
\hline \multirow{3}{*}{$\begin{array}{l}\text { Adding a } \\
\text { matrix group }\end{array}$} & Cd $(300 \mathrm{mg} / \mathrm{kg})$ & 0.145 & 0.12 & 0.26 & 0.29 & 0.35 & 0.345 \\
\hline & Cd (600mg/kg) & 0.150 & 0.12 & 0.265 & 0.295 & 0.31 & 0.305 \\
\hline & Contrast & 0.13 & 0.30 & 0.27 & 0.27 & 0.295 & 0.14 \\
\hline \multirow{3}{*}{$\begin{array}{l}\text { No matrix } \\
\text { group }\end{array}$} & $\mathrm{Cd}(300 \mathrm{mg} / \mathrm{kg})$ & 0.0085 & 0.0105 & 0.0105 & 0.010 & 0.0105 & 0.0080 \\
\hline & $\mathrm{Cd}(600 \mathrm{mg} / \mathrm{kg})$ & 0.010 & 0.010 & 0.0090 & 0.011 & 0.010 & 0.0090 \\
\hline & Contrast & 0.010 & 0.0090 & 0.010 & 0.0080 & 0.010 & 0.010 \\
\hline contrast & & 0.10 & 0.10 & 012 & 0.12 & 0.125 & 0.11 \\
\hline
\end{tabular}

According to the soil urease activity (Ure) calculation formula of different culture time of soil urease activity in table 3:

TABle III. Different Culture Time Of SoIl Urease Activity

\begin{tabular}{cccccccc}
\hline Sampling time & 1 & 3 & 5 & 7 & 14 & \\
\hline Cd (300mg/kg) & 1.6 & 0.42 & 5.5 & 7.0 & 9.5 \\
Cd (600mg/kg) & 0.175 & 0.44 & 6.0 & 7.5 & 7.5 & 8.0 \\
Contrast & 0.9 & 0.485 & 6.0 & 6.0 & 7.5 & 0.9 \\
\hline
\end{tabular}

Note: the 24h NH3-N 1G in soil mg number 


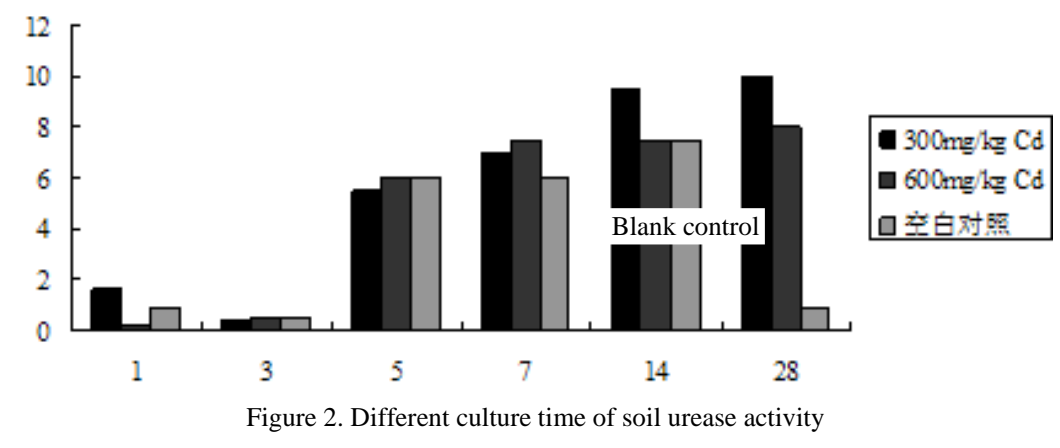

As can be seen, the initial, three soil samples of urease activity decreased slightly, from the beginning of the third day, urease activity increased rapidly, there is no significant difference between urease activity of three soil samples, this trend has continued into the fourteenth day. The fourteenth day, the difference between the experimental group and control group, two experimental groups of urease activity continues to rise, while the control group, the activity decreased sharply. Soil samples with different content of cadmium and cadmium free samples, there is no significant difference, the situation continued until day twenty-eighth of the experiment.

The twenty-eighth day, the difference between the urease activity in the experimental group and the control group, the activity of urease in experimental group was higher than blank control group, the urease activity of urease activity in experimental group and low CD content is slightly higher than that of high cadmium content.

\section{DISCUSSION}

This study uses urea as matrix, based on the enzymatic products of ammonia and phenol hypochlorite reaction blue starch, to analyze the urease activity, With the urease activity in soil nitrogen characterization to analyze the effect of heavy metal Cd on soil microbial activity. The soil without $\mathrm{Cd}$ was considered as the control, to eliminate the effect of ammonia original soil, the effect of different concentrations of $\mathrm{Cd}$ on soil urease activity was analyzed. Research showed that concentrations of Cd has no obvious effect on urease activity and the urease activity showed a rising trend with the incubation time. This trend has continued until day 14. At the end of the experiment, Cd stimulation to the urease activity began to play a role and become stronger and stronger. Urease activity was significantly higher than that of without addition of $\mathrm{Cd}$ in soil. In addition, $\mathrm{Cd}$ content in the soil was lower $(300 \mathrm{mg} / \mathrm{kg})$ and the activity of urease is slightly higher than that of high Cd content in soil $(600 \mathrm{mg} / \mathrm{kg})$, which may be due to high concentrations of Cd resulted in the persecution of effect on microorganism, inhibit the synthesis of urease microorganisms, i.e. Cd on activity of urease activation function is a threshold, in threshold, can promote the urease activity increased, increased microbial decomposition of urea. Once the threshold is exceeded, the decomposition efficiency of urea will reduce the microbial intake and utilization.

\section{V.ACKNOWLEDGEMENTS}

This work was supported by National Natural Science Foundation of China (41101530; 31270586), Science and Technology Development Plan of Shandong Province (2014GSF117029), International Cooperative

Project of Shandong Province (2012GHZ21702)

\section{REFERENCES}

[1] Yu Shou-na, Liao Min, Huang Chang-yong. Effects of cadm ium andm ercury combined pollution on soil urease and acid phosphatase activities. Ch inese Journa l of App lied E co logy, Aug. 2008, 19( 8): 1841-1847

[2] Eneman JD, Potts RJ, Osier M, et al. Suppressed oxidant-induced apoptosis in cadmium adapted alveolar epithelial cells and its potential involvement in cadmium carcinogenesis [J]. Toxicology, 2000, 147 (3): 215-228.

[3] Hartwig A, Beyersmanna D. Biol Trace Elem[M]. Res: 1989, 21: 359365

[4] Moreno JL, Garcia C, Hernandez T. Toxic effect of cadmium and nickel on soil enzymes and the influence of adding sewage sludge. European Journal of Soil Biology, 2003, 54: 377- 386

[5] Zhou Likai. Soil enzymology [M]. Beijing: Science Press, 1987:118159.

[6] Marxm C,Woodm, Jarvis S C. A microplate fluorimetric assay for the study of enzyme diversity in soils[J]. Soil Biology and Biochemistry, 2001, 33(12): 1633- 1640

[7] Meng Qingfeng, Yang Jingsong, Yao Rongjiang, Yu Shipeng, Zhang Chunyin, Ji Ronglong. Influence of single and combined pollutions of heavy metal on soil enzyme activity. Ecology and Environmental Sciences, 2012, 21(3): 545-550. 